\title{
The Comparison of Adjustable Single-incision Mini Sling and Transobturator Tape for the Treatment of Stress Urinary Incontinence
}

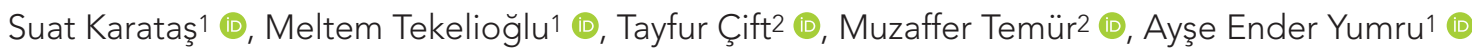 \\ ${ }_{1}^{1}$ istanbul Şişli Hamidiye Etfal Training and Research Hospital, Department of Obstetrics and Gynaecology, İstanbul, Turkey \\ ${ }^{2}$ Bursa Yüksek İhtisas Training and Research Hospital, Department of Obstetrics and Gynaecology, Bursa, Turkey
}

Cite this article as: Karataş S, Tekelioğlu M, Çift T, Temür M, Ender Yumru A. The Comparison of Adjustable Single-incision Mini Sling and Transobturator Tape for the Treatment of Stress Urinary Incontinence. JAREM 2020;10(1): 36-40

\begin{abstract}
Objective: The aim of the study was to compare the efficacy and complications of adjustable single-incision mini-sling (A-SIMS) with transobturator tape (TOT) in surgical management of female urinary incontinence.

Methods: The results of 54 patients performed A-SIMS and TOT were evaluated retrospectively. Inclusion criteria were stress urinary incontinence with valsava leak point pressure $<60 \mathrm{~cm} \mathrm{H} 2 \mathrm{O}$ and at least one-year follow-up. Exclusion criteria were pelvic organ prolapsus, concominant or previous genitourinary surgery and patients without urodynamic assessment. Patients were enrolled into two groups as A-SIMS and TOT, each group included 27 patients. Results of the operations (postoperative hemoglobin decrease, operation time, perioperative complication, urinary retention, postoperative pain) and efficacy of the surgery (objective cure rate, subjective cure rate, failure rate) were compared.

Results: Both of the groups were similar according to the patients characteristics. The mean follow-up period was 21.5 and 17.7 months in TOT and A-SIMS groups, respectively. The difference between the two groups according to objective cure rate, subjective cure rate and failure rate was not statistically significant. Postoperative hemoglobin decrease and operation time in the A-SIMS group were significantly lower than in the TOT group. Five patients had postoperative pain in the TOT group. However, no pain was revealed in the A-SIMS group. Besides, no perioperative complication was revealed in both of the groups.

Conclusion: In short-term period, A-SIMS is as effective and safe as TOT in the surgical management of female urinary incontinence. However, A-SIMS may be superior as a simple procedure having shorter operation time.
\end{abstract}

Keywords: Mini-sling, tot, stress urinary incontinence

\section{INTRODUCTION}

Stress urinary incontinence (SUI) complaint is defined as involuntary urinary incontinence with exertion, exercise, sneezing or coughing (1-3). Urinary incontinence in women causes distress and negatively affects their daily lives. Urinary incontinence incidence varies between 10 and $40 \%(4,5)$. This problem affecting approximately $50 \%$ of incontinent women all over the world is primarily treated conservatively and medically (6). However, failed conservative treatments often make surgical treatment necessary. Surgical treatment is somewhat developed and aimed at correcting urethral hypermobility that causes SUI (7). Incontinence is more common in older women than in younger women (4). Obesity and childbirth are seen as general risk factors in SUI $(8,9)$. Stress is the gold standard midurethral sling operation in the treatment of urinary incontinence and has a cure rate of 70$90 \%$ when considering the long-term results (10). Transobturator tape (TOT), tension-free vaginal tape (TVT) or adjustable singleincision mini-sling (A-SIMS) can be successfully applied according 
retention after operation, and postoperative pain information were evaluated as the results of the application.

In order to evaluate the effectiveness of the application, the objective treatment, subjective treatment, and inadequate treatment criteria recorded in the patients' most recent controls (16-30 months) were used. Objective therapy was defined as the negative cough stress pad test (CSPT) and bladder volume of $150 \mathrm{cc}$ and above, and subjective treatment was defined as CSPT positive and bladder volume less than $150 \mathrm{cc}$. Continuation of incontinence was accepted as inadequate treatment.

The authors declared that the study was conducted in accordance with the principles of the World Medical Association Declaration of Helsinki "Ethical Principles for Medical Research Involving Human Subjects" (amended in October 2013).

\section{Surgical Technique}

All operations were performed under spinal anesthesia and by two different surgeons. In TOT application, with Supro SUI (Klas Medikal, Turkey), one side of the groin was inserted with the aid of a $1.2 \mathrm{~cm}$ wide monoflament polypropylene knitting needle, using standard outward-inward technique. The obturator foramen was passed and it was placed in the periurethral area prepared previously. The other end of the knitting was taken out of the other groin in the same way. The knitting ends were cut under the skin to allow tension-free application. A-SIMS application was performed as described by Petros and Richardson (17). In A-SIMS, the knitting is the same type but shorter and is applied through a single vaginal incision. The contasure-needleness (Neomedic Int., Spain) sling used in this study has no anchor and has facial pockets on both ends that provide post-insertion stabilization.

\section{Statistical Analysis}

SPSS v. 16.0 package program (SPSS Inc., Chicago, IL, USA) was used for the statistical analysis of the data. The normal distribution of data in both groups was evaluated with the KolmogorovSimirnov test. Comparison of numerical data with normal distribution between groups was performed with the Student's t-test and comparison of non-normally distributed numerical data was performed by using the Mann-Witney $U$ test. The chi-square test was used for categorical variables. Average and standard deviation values of both groups were calculated separately. Values of $p<0.05$ were considered statistically significant.

\section{RESULTS}

Demographic data of 54 patients included in the study are shown in Table 1. There was no significant difference between the groups in terms of age, BMI, parity, menopausal status and smoking. When we evaluated the ages of the patients, the mean age of the A-SIMS group was $47.41 \pm 10.89$ years, while the mean age of the TOT group was $52.22 \pm 10.98$ years. While the mean age was higher in the TOT group, the difference between the groups was not found to be statistically significant $(p=0.112)$. When the parity numbers of the patients were analyzed, it was $3.26 \pm 1.99$ and hospitalization times, perioperative complications, urinary 
in the mini-sling group and $2.74 \pm 2.29$ in the TOT group. In both groups, the number of births of the patients was more than 2 , but the difference between the groups was found to be statistically insignificant after comparing the groups $(p=0.380)$. Vaginal delivery in the TOT group was higher than in the A-SIMS group. In the A-SIMS group, cesarean delivery was higher than in the TOT group.

When the operation results were evaluated in both groups, the operation time was found to be significantly shorter in the SIMS group $(p<0.001)$. Similarly, the decrease in postoperative hemoglobin was found to be significantly higher in the A-SIMS group ( $p<0.007)$. In the TOT group, 3 patients had urinary retention and 5 patients developed early postoperative groin pain. No other perioperative complications developed in both groups. No significant difference was found between the groups in terms of length of stay (Table 2).

The effectiveness of the treatments applied was evaluated by the examination performed at the last control of the patients. The shortest follow-up was 16 months, and the longest was 30 months. The mean follow-up time was 21.5 months in the TOT group and 17.7 months in the A-SIMS group. When we evaluated the objective treatment, subjective treatment, and inadequate treatment rates, it was found that there was no significant difference between the two groups (Table 3).

\section{Table 1. Demographic data of patients}

\begin{tabular}{|c|c|c|c|}
\hline & A-SIMS** $(n=27)$ & TOT $^{\star \star \star}(n=27)$ & $p$ \\
\hline Age & $47.41 \pm 10.89$ & $52.22 \pm 10.98$ & 0.112 \\
\hline$B M I^{\star \star \star \star}$ & $30.00 \pm 4.53$ & $28.92 \pm 6.03$ & 0.461 \\
\hline Parity & $3.26 \pm 1.99$ & $2.74 \pm 2.29$ & 0.380 \\
\hline Vaginal delivery & $21(77.8 \%)$ & $26(96.3 \%)$ & $0.043^{*}$ \\
\hline Caesarean & $6(22.2 \%)$ & $1(3.7 \%)$ & $0.043^{*}$ \\
\hline Post menopause & $13(48 \%)$ & $16(59.3 \%)$ & 0.115 \\
\hline Smoking & 12 (54.5\%) & $10(45.5 \%)$ & 0.413 \\
\hline
\end{tabular}

\section{Table 2. Operative results}

\begin{tabular}{|l|l|l|l|}
\hline & $\begin{array}{l}\text { A-SIMS** } \\
(\mathbf{n = 2 7 )}\end{array}$ & $\begin{array}{l}\text { TOT*** } \\
(\mathbf{n = 2 7 )}\end{array}$ & $\mathbf{p}$ \\
\hline $\begin{array}{l}\text { Duration of operation } \\
\text { (minutes) }\end{array}$ & $15,81 \pm 3,58$ & $25.41 \pm 6.82$ & $<0.001^{*}$ \\
\hline $\begin{array}{l}\text { Length of hospitalization } \\
\text { (day) }\end{array}$ & $2,85 \pm 0,90$ & $3.52 \pm 1.52$ & 0.057 \\
\hline $\begin{array}{l}\text { Perioperative complication } \\
\text { Decreased postoperative }\end{array}$ & 0 & 0 & - \\
\hline hemoglobin level (g/dL) & $1,31 \pm 0,60$ & $1.78 \pm 0.61$ & $0.007^{*}$ \\
\hline \begin{tabular}{l} 
Urinary retention \\
\hline Postoperative pain
\end{tabular} & 0 & $3(11.1 \%)$ & 0.075 \\
\hline $\begin{array}{l}* \text { p }<0,05,{ }^{* * A-S I M S: ~ a d j u s t a b l e ~ s i n g l e-i n c i s i o n ~ m i n i-s l i n g, ~} \\
\text { tape }\end{array}$ & & $5(18.5)$ & 0.019 \\
\hline
\end{tabular}

\section{DISCUSSION}

In our study, TOT and A-SIMS procedures applied to patients with urinary incontinence due to SUI were evaluated. When the data of our study were evaluated, the superiority of both methods to each other could not be determined statistically in the comparison of the A-SIMS procedure and the TOT procedure. In the literature, many studies evaluating patients undergoing anti-incontinence surgery due to SUI have been conducted $(18,19)$. In a study by Pascom et al. (2), 130 women undergoing mini-sling (SIMS) and TOT operations from a single incision were followed up for 36 months. In the study, they determined that both surgical procedures had a similar effect in improving the quality of life. In the study, they also determined that the mini-sling operation required more revision procedures compared to the TOT operation. In addition, after 3-year follow-up in the group of patients who underwent TOT, they determined less persistence in SUI. As a result, they reported that although both groups had similar satisfaction rates for surgery in the postoperative 36-month follow-up, TOT operation had higher treatment rates in SUI compared to A-SIMS operation.

In our study, TOT and A-SIMS were applied to patients with similar characteristics (age, BMI, number of vaginal births) as SUI surgery, the results of the patients were evaluated, and no statistically significant difference was found regarding the results of both groups.

In a study by Schellart et al. (14), 225 patients who underwent minisling and TOT were followed for 24 months and the results of the patients were compared with each other at the end of the study. The study was started with 225 patients, and 32 patients refused to participate in the study and the study continued with 193 patients. 20 patients after the first year follow-up and 32 patients after the second year of follow-up were excluded. The study ended with 141 patients. The age, BMI, parity and postmenopausal status of the patients were evaluated and no difference was found between the groups. In the study, the treatment rates of TOT and mini-sling patients were similar in the first and second years, and the side effects were similar. In the study, the superiority of TOT or minisling to each other could not be determined after 2 years. In our study, we could not determine the superiority of both methods to each other.

In a meta-analysis by Zhang et al. (9), they compared mini-sling and TOT surgery in female SUI surgery. In the study, 154 studies were evaluated and meta-analysis was completed with 5 randomized controlled studies. As a result of the study, they found that the mini-sling operation was safe and effective in SUI in women. In

\begin{tabular}{|c|c|c|c|}
\hline & $\begin{array}{l}\text { A-SIMS* } \\
(n=27)\end{array}$ & $\begin{array}{l}\text { TOT** } \\
(n=27)\end{array}$ & $p$ \\
\hline Objective therapy & 25 (92.6\%) & 23 (85.2\%) & 0.386 \\
\hline Subjective therapy & $3(11.1 \%)$ & $2(7.4 \%)$ & 0.639 \\
\hline Inadequate therapy & $1(3.7 \%)$ & $1(3.7 \%)$ & 0.755 \\
\hline
\end{tabular}


In our study, after 1-year follow-up of the patients, the objective and subjective treatment rates in the A-SIMS group were higher than the TOT group (92.6\%-11.1\% versus $85 \%-7.4 \%)$, but there was no statistically significant difference between the two groups. Our results are similar to the study done by Sivaslıoglu et al. (15) In this study, the objective treatment rates obtained at the end of the 3-year follow-up in the TOT and A-SIMS (TFS) groups were reported as $90 \%$ and $84 \%$, respectively, and no statistically significant difference was found.

In the first studies comparing SIMS and traditional MUSs, SIMSs were found to be lower according to objective treatment rates (11). However, these studies included third generation MUSs, called TVT-secure, that were withdrawn from the market in 2013 due to poor clinical results. After that, promising results were obtained in studies that excluded TVT-secure $(16,23)$. In two separate metaanalyzes (6.9) that included five randomized controlled trials comparing A-SIMS and MUSs in 2015 and eight studies in 2018, A-SIMS was reported to be as effective as MUS when considering short-term results (12 months).

This result may be due to the fact that both techniques were developed with the same surgical principle. However, it has been reported that SIMS application does not show perioperative complications in standard MUS applications and its operation time is shorter because it is less invasive and easy (9).

In our study, shorter operation times $(p<0.001)$ and higher postoperative hemoglobin decrease $(p=0.007)$ were found statistically significant in the A-SIMS group. Although the duration of hospitalization in the A-SIMS group was shorter, there was no statistically significant difference in terms of length of stay between the two groups $(p=0.057)$. Perioperative complications did not develop in both groups.

In TOT application, bladder, obturator nerve and vessels can be injured during the transition from obturator foramen. Similarly, passage through the adductor tendons and skin is thought to cause postoperative groin and thigh pain (13). In the literature, it has been reported that postoperative pain formation with SIMS is much less than transobturator slings (14). The absence of transition from the obturator foramen and exit from the skin in SIMS application prevents these complications and reduces the possibility of postoperative pain.

In our study, postoperative groin pain was observed in 5 patients (18.5\%) in the TOT group. In addition, although 3 patients (11.1\%) developed postoperative urinary retention, pain and urinary retention were not observed in the A-SIMS group.

Considering the limitations of our study, it is remarkable that it is retrospective and the number of cases is not very high. However, the fact that the data of the study are single-centered and that surgical procedures are performed by the same surgeons are among the advantages of our study.

\section{CONCLUSION}

A-SIMS or TOT procedures applied in the treatment of SUI are successful and have not been proven to be superior to each other. 
Although advantages such as the mini-sling procedure's being less invasive and short length of hospital stay are short, we are of the opinion that patient-related risks should be discussed before decision-making for the selection of surgical procedure and type in addition to the experience of surgeon.

Ethics Committee Approval: Ethics committee approval was not obtained since the required data were obtained by retrospectively examining patient records.

Informed Consent: It was obtained.

Peer-review: Externally peer-reviewed.

Author Contributions: Surgical and Medical Practices - S.K.; Concept T.Ç.; Design - Me.T.; Supervision - B.Ç.; Resources - B.Ç.; Data Collection and/or Processing - M.T.; Analysis and/ or Interpretation - T.Ç.; Literature Search - A.E.Y.; Writing Manuscript - S.K., M.T., T.Ç., M.T., A.E.Y.

Conflict of Interest: The authors have no conflict of interest to declare.

Financial Disclosure: The authors declared that this study has received no financial support.

\section{REFERENCES}

1. Haylen BT, de Ridder D, Freeman RM, Swift SE, Berghmans B, Lee J, et al. An International Urogynecological Association (IUGA)/International Continence Society (ICS) joint report on the terminology for female pelvic floor dysfunction. Int Urogynecol J 2010; 21: 5-26.

2. Pascom ALG, Djehdian LM, Bortolini MAT, Jarmy-Di Bella ZIK, Delroy CA, Tamanini JTN, et al. Randomized controlled trial comparing singleincision mini-sling and transobturator midurethral sling for the treatment of stres urinary incontinence: 3-year follow-up results. Neurourol Urodyn. 2018; 37: 2184-90.

3. Kavia R, Rashid T, Ockrim J. Stress urinary incontinence. J Clin Urol 2013; 6: 377-90.

4. Cavkaytar S, Kokanali MK, Ozer I, Erkilinc S, Aksakal OS, Doganay M. Effect of pregnancy and delivery on urinary incontinence after the midurethral sling procedure. Int Urogynecol J 2015; 26: 693-8.

5. Melville JL, Katon W, Delaney K, Newton K. Urinary incontinence in US women: a population-based study. Archives of Internal Medicine 2005; 165:537-42.

6. Bai F, Chen J, Zhang Z, Zheng Y, Wen J, Mao X, et al. Adjustable singleincisionmini-slings (Ajust) versus other slings in surgical management of femalestress urinary incontinence: ameta-analysis of effectiveness and complications. BMC Urology 2018; 18: 44.

7. Shamout $S$, Campeau L. Stress urinary incontinence in women: Current and emerging therapeutic options. Can Urol Assoc J 2017; 11: 155-8.

8. Fultz NH, Herzog AR. Prevalence of urinary incontinence in middle aged and older women: a survey based methodological experiment. J Aging Health. 2000; 12: 459-69.

9. Zhang P, Fan B, Zhang P, Han H, Xu Y, Wang B, et al. Meta-analysis of female stress urinary incontinence treatments with adjustable singleincision mini-slings and transobturator tension-free vaginal tape surgeries. BMC Urol. 2015; 15: 64.
10. Lin L, Huang MC, Su TH, Lau HH. Comparison between tensionfree vaginal tape and transobturator tape in treating stress urinary incontinence after vaginal mesh surgery. Taiwan J Obstet Gynecol. 2018; 57: 528-31.

11. Abdel-Fattah M, Ford J, Lim C, Madhuvrata P. Single-incision minislings versus standard Midurethral slings in surgical management of female stress urinary incontinence: a meta-analysis of effectiveness and complications. Eur Urol. 2011; 60: 468-80.

12. Abdel-Fattah M, Agur W, Abdel-All M, Guerrero K, Allam M, Mackintosh A et al. Prospective multi-centre study of adjustable single-incision mini-sling (Ajust $($ ) in the management of stress urinary incontinence in women: 1-year follow-up study. BJU Int. 2012; 109: 880-6.

13. Thomas TN, Siff LN, Jelovsek JE, Barber M. Surgical Pain After Transobturator and Retropubic Midurethral Sling Placement. Obstet Gynecol. 2017; 130: 118-125.

14. Schellart RP, Oude Rengerink K, Van der Aa F, Lucot JP, Kimpe B, Dijkgraaf MG, et al. A randomised comparison of single-incision versus traditional transobturator midurethral sling in women with stress urinary incontinence: results of a 24-month follow-up. Int Urogynecol J 2016; 27: 871-7.

15. Sivaslıoglu SS, Unlubilgin E, Aydogmus S, Keskin L, Dolen I. A prospective randomized controlled trial of the transobturator tape and tissue fixation mini sling in patients with stress urinary incontinence: 5-year results. J Urol 2012; 188: 194-9.

16. Tutolo M, De Ridder DJ, Montorsi F. A minimum of 1year follow-up for MiniArc single incision slings compared to Monarc transobturator slings: an analyses to evaluate durability of continence and medium-term outcomes. Neurourol Urodyn 2017; 36: 803-7.

17. Petros PE, Richardson PA. Midurethral tissue fixation system -a micromethodfor cure of stress incontinence- preliminary report. Aust NZ J Obstet Gynaecol 2005; 45: 372-5.

18. Rechberger T, Wrobel A, Zietek A, Rechberger E, Bogusiewicz M, Miotla P. Transobturator midurethral sling: What should patients expect after surgery? Int Urogynecol J 2018; 29: 55-61.

19. Rudnicki M, von Bothmer-Ostling K, Holstad A, Magnusson C, Majida $M$, Merkel $C$, et al. Adjustable mini-sling compared with conventional mid-urethral slings in women with urinary incontinence. A randomized controlled trial. Acta Obstet Gynecol Scand 2017; 96: 1347-56.

20. Nambiar A, Cody JD, Jeffery ST. Single-incision sling operations for urinary incontinence in women. Cochrane Database Syst Rev 2014; 1:CD008709.

21. Kokanalı MK, Cavkaytar S, Kokanalı D, Aksakal O, Doganay M. A comperative study for short-term surgical outcomes of midurethral sling procedures in obese and non-obese women with stress urinary incontinence. J Obstet Gynaecol 2016; 36: 1080-5.

22. Natale F, Illiano E, La Penna C, Balsamo R, Costantini E. Mixed urinary incontinence: A prospective study on the effect of trans-obturator midurethral sling. Eur J Obstet Gynecol Reprod Biol 2018; 221: 64-9.

23. Jiao B, Lai S, Xu X, Zhang M, Diao T, Zhang G. A systematic review and meta-analysis of single incision mini-slings (miniArc) versus transobturator miduretral slings in surgical management of female stress urinary incontinence. Medicine 2018; 97: 14. 